\title{
Sebastianismo e Messianismo em Os Sertões
}

\author{
Simão Pedro dos Santos \\ Universidade Severino Sombra, CELCSAH/CECS, \\ revisor.uss@gmail.com
}

\begin{abstract}
Resumo: $O$ artigo trata da questão do messianismo sebástico de origem portuguesa, que ultrapassa as fronteiras de além-mar e aporta em terras brasileiras que vão do Rio de Janeiro a Minas Gerais e do Sul do país ao Nordeste, onde é mais forte, toma ares de nacionalismo místico-políticoreligioso recorrente, sobretudo, no sertão e agreste em movimentos que terminam, todos, por desencadear extrema violência não só oficial, na defesa dos poderes constituídos, mas também dos grupos fanatizados, na defesa de seu território e da fé em que acreditam. O messianismo nordestino e brasileiro se dá até os dias atuais desdobrados em vários aspectos e concepções, a exemplo do messianismo moderno e das engrenagens urbanas, porém com vistas às grandes saídas políticas e cidadãs.
\end{abstract}

Palavras-chave: Messianismo. Sebastianismo. Nordeste. Fé.

\section{Sebastianism and Messianism in The Backlands}

\begin{abstract}
The article deals with the issue of Sebastian messianism of Portuguese origin, which goes beyond the overseas borders and brings it into Brazilian lands, ranging from Rio de Janeiro to Minas Gerais and from the South to the Northeast, where it is stronger, and takes a nationalist, mystic, political and religious recurrent aspect, especially in the wilderness, in movements that all end up unleashing extreme violence, not only official, in the defense of the constituted powers, but also involve groups of fanatics in the defense of their territory and their beliefs. Brazilian northeastern messianism is found to the present day unfolded into into various aspects and concepts, such as the modern messianism and the urban gears, but with views to the sound needs of citizens and politics.
\end{abstract}

Keywords: Messianism. Sebastianism, Northeast, Faith.

\section{Sebastianismo y el Mesianismo en El Sertón}

Resumen: El artículo trata de la cuestión del mesianismo sebastianista de origen portuguesa, que va más allá de las fronteras de ultramar y aporta en tierras brasileñas que van desde Rio de Janeiro hacia Minas Gerais y del Sur del país hacia el Noreste, donde es más fuerte, con aires de um nacionalismo místico-políticoreligioso recorriente, sobretodo, en el "sertão" y "agreste" en movimientos que terminan, todos, por desencadenar extrema violencia no sólo oficial, en defensa de los poderes constituidos, sino también de los grupos fanatizados, en defensa de 
su territorio y de la fé en que creen. El mesianismo nordestino y brasileño ocurre hasta hoy desplegado en varios aspectos y conceptos, a ejemplo del mesianismo moderno y de los engrenajes urbanos, pero con vistas a grandes salidas políticas y ciudadanas.

Palabras claves: Messianismo. Sebastianismo. Noreste. Fé.

\section{Introdução}

O sebastianismo é o messianismo português. Representa, portanto, a espera e a busca pela redenção. Os primeiros cultos sebastianistas resultam da opressão sofrida por Portugal quando da invasão espanhola ao seu território, episódio que terminou por identificar D. Sebastião como o sinal verdadeiro do redentor. Como em toda a história da humanidade o sonho de libertação é a marca de qualquer povo oprimido por outro, o que se deu a Portugal entre a segunda metade do século XVI e as primeiras quatro décadas do XVII.

Percebe-se que o messianismo é o culto da fé em um ser ungido, escolhido por Deus para salvar os pobres e oprimidos não só numa conotação religiosa, mas naquela de natureza política, esta última, com seus desdobramentos de ordem econômica e social. Nesse caso, podemos afirmar que o messianismo engloba, queiramos ou não, contextos que não só teológicos, mas ainda sociológicos. Do ponto de vista ocidental, judaico-cristão, messias são, portanto, entre outros, um Moisés, um Jesus Cristo, um D. Sebastião.

O sebastianismo é culto que impregna a cultura portuguesa desde antes de sua invasão, e após esta, pela Espanha em 1580. Na história mais recente, Fernando Pessoa, poeta modernista português, traz temática de modelo sebastianista em Mensagem, um de seus mais bem elaborados textos, escrito entre 1912 e 1934, e tentativa de resgatar o Portugal do passado e repensar o decadente. Pretensão, ou não, no seu para a Revista Águia, em 1912, o poeta anunciaria a sua obra como super Camões.

Entre outras passagens, a figura de D. Sebastião é invocada em O Desejado:

Onde quer que, entre sombras e dizeres,

Jazas, remoto, sente-te sonhado,

E ergue-te do fundo de não-seres

Para teu novo fado!

Vem, Galaaz com pátria, erguer de novo,

Mas já no auge da suprema prova,

A alma penitente do teu povo

À Eucaristia Nova.

Mestre da Paz, ergue teu gládio ungido,

Excalibur do Fim, em jeito tal

Mosaico - Revista Multidisciplinar de Humanidades, Vassouras, v. 3, n. 1, p. 23-34, jan./jun., 2012 
Que sua Luz ao mundo dividido

Revele o Santo Gral! (Mensagem, 1998, p.34)

Todo povo que é subjugado por outro tem de se adaptar aos aspectos culturais do invasor, a saber: linguísticos, religiosos, políticos, econômicos e sociais, o que o faz no trajeto histórico não só se sentir humilhado, como em muitos casos, se rebelar, conforme é típico dos processos de colonização ou de opressão de um povo sobre outro, embora com o tempo essas culturas também se entrelacem e se sobreponham. Por outro lado, quando esses grupos sociais invadidos não dispõem de forças bélicas suficientes, ou se as têm frágeis para um enfrentamento de caráter libertário, essa força se transferirá para um Messias, a quem é atribuído o mérito de libertador.

Isso ocorreu aos hebreus, quando escravos no Egito; aos antigos palestinos e israelitas, sob jugos vários (ao longo de sua história), inclusive dos romanos. E até propostas como as do marxismo, que, igualmente e inclusive, por ideal político de justiça e igualdade sociais, não foge à sugestão messiânica, uma vez que, com seu materialismo dialético, traz como fundo a libertação do proletariado. São messiânicos o cristianismo e suas ramificações que vão do catolicismo romano ao protestantismo, todos, com um olhar virtual e apocalíptico de justiça.

\section{O Encoberto: um rei-libertador e a fé católica mais do que largueada}

D. Sebastião morre no Marrocos, especificamente em Alcácer Quibir, quando em luta contra os mouros, a quem considerava infiéis, isto é, não cristianizados, e a quem a todo custo desejava evangelizar. $\mathrm{O}$ ano de seu desaparecimento é o de 1578, 4 de agosto, e seu culto se dá em um Portugal dominado pela Espanha da dinastia filipina, $(1580$ - 1640) e se estende até pelo menos boa parte do século XX.

Ressalte-se que o culto messiânico/sebastianista é anterior àquele que se presta a D. Sebastião, mormente, por haver entre os portugueses rudimentos de uma fé messiânica com base nas profecias, em quadrinhas populares, ditadas por um habitante de Trancoso de nome Gonçalo Anes ou Eanes, também chamado de Gonçalo Eanes Trancoso, cristãonovo, sapateiro de profissão, conhecido ainda pela alcunha de Bandarra.

Será interessante lembrar que D. Sebastião é identificado como o Encoberto de quem falara o acima referido sapateiro desde o início do século XVI. Os acontecimentos do final daquele século, com a invasão espanhola levam os portugueses à busca de um redentor, uma vez que empobrecidos e dominados pelo reino vizinho, veem em D.Sebastião seu grande Messias. As evidências da morte, embora não comprovada, do rei-aventureiro e o não aparecimento de seu corpo fomentam a crença de que o monarca verdadeiramente não havia morrido na famosa Batalha do Marrocos. Pelo contrário, inaugura-se o crédito na sua volta um dia. A invasão de Portugal pela Espanha é o momento ideal para o rei libertador voltar.

Evidentemente, a permanência desse mito em terras portuguesas haveria, como é natural, de se transferir para as terras onde o reino se expandira. Desse modo, o Brasil passa 
a professar também uma fé messiânico-sebastianista. Pelas terras de cá o culto a $\mathrm{D}$. Sebastião se dá igualmente em situações de crises de ordem social, política, econômica e até religiosa, já que quase sempre a Igreja foi uma ausência entre as camadas populares. Surge, desse modo, a busca pela redenção por meio de uma fé católico-popular e de uma política também popular, calcadas em ideais de libertação.

No Brasil, é certo que o sebastianismo terminaria por alcançar a portugueses aqui estabelecidos - pobre e ricos -, mas também atinge as camadas populares mestiças, que passam a cultuar o mito, dando-lhe feição toda brasileira. Apesar de não haver indícios de sebastianismo colonial e de não se precisar quando esse culto por aqui aporta e toma corpo, dá-se conta, todavia, e com segurança, de grandes e consolidadas manifestações sebásticas durante o todo o século XIX.

Entre alguns portugueses do século XIX no Brasil houve uma espécie de culto político e nacionalista cuja proposta implicava na volta do sebastianismo. Era, porém, um sebastianismo de ordem mais saudosista-religioso/nacionalista do que político no sentido estreito desse último termo, além, precisamente, de o caráter religioso apresentar conotação popular, como é pertinente a esse culto. Eram esses portugueses senhores abastados radicados no Rio de Janeiro, então corte do Império joanino no Brasil, ou de outros lugares, como veremos abaixo. Notemos o que escreve a esse respeito o viajante inglês Jonh Luccok em crônica do primeiro quartel do século XIX, com exatidão, 1816:

[...] Tanto isso como os outros demais fatos inclinaram-me a dar crédito ao que já me haviam dito, a saber, que meu amigo pertencia a uma seita chamada sebastianismo, como alguns poucos dos quais já casualmente tenho travado relações. São sinceramente devotos na sua crença em Deus e ardentes de amor pelo Redentor, mas seguem os ritos da Igreja, mais por educação que por convicção, mantendo a muitos respeitos, em relação aos católicos, a mesma posição que, perante os protestantes ingleses, ocupam os puritanos. (Notas sobre o Rio de Janeiro, 1942, p. 236).

Ainda dois viajantes, Von Martius e Spix, dão testemunhos de seita sebastianista numa Minas Gerais de 1817:

O porte de nosso distinto hospedeiro, homem grisalho, era tanto solene, e, involuntariamente, nos fazia lembrar os quakers. De fato, ele era também um dos adeptos do sebastianismo, que estão sempre à espera do Rei D. Sebastião, morto na batalha de Alcácer-Quibir, contra os mouros, e com isto a volta da mais gloriosa época do reino de Portugal. Estes sebastianistas, que se distinguem por sua atividade, economia e riqueza, são em número maior no Brasil, e, especialmente em Minas Gerais, que na pátria-mãe. (Viagem pelo Brasil, 1938, p.370). 
Interessa, porém, perceber que o sebastianismo mais importante adaptado à realidade brasileira é àquele igualmente popular, mas que se estabelece em meio às comunidades menos favorecidas, pois representa ideal de mais esperança e fé. Do contrário, sem ser redentor, que sentido faria esse culto entre as camadas populares?

A história oficial, embora não divulgue em manuais escolares, dá conta de um primeiro culto sebástico de natureza popular do Brasil, acontecido em 1819, e diferente daquele praticado pelos ricos portugueses aqui radicados. Ocorrido no agreste pernambucano, precisamente na cidade de Bonito, em lugar denominado Serra do Rodeador, um foco sebastianista se fez realidade mediante um grupo de fanáticos liderado por um certo Silvestre João dos Santos. Todos a acreditar na volta de D. Sebastião para partilhar riquezas e bens. O movimento sobrevive por um ano e é trucidado por forças militares de Pernambuco capitaneadas pelo marechal Luís Antônio Salazar Moscoso.

Outra notícia que se tem de movimento sebastianista ocorreu em Vila Bela, hoje Serra Talhada, Pernambuco, de 1836 a 1838. Conhecido por Reino da Pedra Bonita, atualmente Pedra do Reino, foi aglomerado de fiéis conclamados e comandados por João Antônio dos Santos, e ficou marcado por dar crédito também à volta de D. Sebastião, que, encantado em duas pedras geminadas e cilíndricas em forma de torres, de lá sairia para distribuir riquezas ao séquito faminto, mas esperançoso.

Esse episódio desencadeou a seguinte tragédia: os crentes são instigados por seu líder a sacrifício humano e de animais para tornar possível o desencantamento do rei, a saber, D. Sebastião, por eles desejado. Dessa forma, velhos, crianças, mulheres e homens feitos passam por morte ao fio de espadas e têm o sangue aspergido nas acima referidas pedras cilíndricas com o fim de desencantar o rei, que, uma vez aparecido, viria a executar os sonhos de uma real terra prometida. Cães são também sacrificados para voltarem, segundo a superstição da crença, como dragões que protegerão o reino que se estabeleceria na localidade. A comunidade de fanáticos é dizimada em 1838 pela polícia de Pernambuco, sob o comando de Manuel Pereira da Silva. Mais uma vez a crônica do Nordeste do Brasil tem desfecho terrível e sob o pano de fundo da religiosidade fanatizada.

\section{Messianismo Conselheirista: o sertão vai virar praia}

O mais importante movimento messiânico do Brasil ocorreu em Canudos e representa a força e a resistência do homem na defesa do meio e da fé. Esse ajuntamento messiânico de caráter sebastianista se deu sob a liderança do beato Antônio Vicente Mendes Maciel, o Antônio Conselheiro, de 1893 a 1897, às margens do rio Vaza-Barris, na localidade de Monte Santo, Bahia.

O foco sebastianista tem em Antônio Conselheiro orientação espiritual e moral, com prevalência da ordem religiosa e prédica da espera e consequente vinda de D. Sebastião, Visita nos vem fazer/ Nosso rei D. Sebastião./ Coitado daquele pobre/ Que estiver na lei do cão! [Cf.: Os sertões, 2002, p.239] E isto é o que motivou correria generalizada ao local, face à necessidade que o povo tem de se afirmar em eterna busca por melhoria de vida e do bem-estar em todas as suas conotações. Resulta deste fato uma das mais tristes memórias a que o Brasil não deveria esquecer, tamanho o massacre desfechado pelas 
forças militares oficiais. Um crime a que deveríamos denunciar, como lembra Euclides da Cunha em sua obra mais famosa.

Dividido em três partes, Os sertões trazem a princípio, um apanhado da terra sertaneja onde se dá o conflito e sua natureza; em seguida faz um estudo do homem como integrante do meio social, para culminar com o que o autor chamou de a luta. Neste artigo damos foco ao homem canudense como ser integrante e arraigado ao contexto religioso, social, econômico e cultural e, portanto, como elemento formador da cultura e da realidade a que pertenceu.

Na saga da fé sertaneja, como já vimos, o sebastianismo esteve presente em pelo menos três movimentos, os quais sempre sofreram repressão, por medo de crescimento massivo e foco de revoltosos por parte do governo, por pressão da própria igreja ou de parcela do povo, quase sempre coronéis ou fazendeiros, insatisfeitos com movimentos dessa ordem, em repelir automático. Interessante notar que em todos os eventos dessa ordem, lá estavam a reprimir, em maior ou menos escala, essas três classes privilegiadas da sociedade. Seja como for, fato é que essas aglomerações místicas terminam por sofrer represálias e ao governo é sempre tributado o agir, no sentido de dizimar, segundo sua linguagem, tudo aquilo que ameaça a ordem pública, mesmo que ordem pública seja um simulacro para atender a coronéis, fazendeiros, à igreja, ou seja, aos aliados e seus caprichos.

Como afirma Euclides da Cunha, Canudos não se rendeu e foi até as últimas consequências com seu messianismo. Para entendermos o contexto no tocante ao sebastianismo de Canudos, basta-nos ler as pregações do Conselheiro com seus sermões barrocosertanejos:

Em verdade vos digo, quando as nações brigam com as nações, o Brazil com o Brazil, a Inglaterra com a Inglaterra, a Prússia com a Prússia, das ondas do mar D. Sebastião sahirá com todo o seu exército.

Desde o princípio do mundo que encantou com todo seu exército e o restituio em guerra.

E quando encanto-se afincou a espada na pedra, ella foi até os corpos e lhe disse:

Adeus mundo!

Até mil e tantos a dois mil não chegarás! (Os sertões, 2002. p. 175).

Clara está a mistura de elementos na prédica de Antônio Conselheiro. Note-se o amálgama do texto bíblico neotestamentário dos discursos de Cristo, com uma visão apocalíptica do fim do mundo e de sua consequente restauração. Mas a restauração do mundo de Conselheiro se dá mediante o messianismo sebástico. É D. Sebastião, que, saído do mar com seu exército, trará a todo o povo a libertação e a redenção. Interessante perceber que D. Sebastião tem a feição de personagem das tão medievais novelas de cavalaria, pois no sermão do velho profeta de Quixeramobim há um misto de ciclo arturiano, céltico, da busca do Santo Graal com o próprio rei português desaparecido. É o Nordeste sem fronteiras de tempo e de espaço. 
O grande milagre que prega Conselheiro é na verdade, a restauração da monarquia e o fim da incipiente república brasileira. Missão inclusive, somente cumprida com a volta de D. Sebastião:

Neste dia quando sair com seu exército tira a todos no fio da espada deste papel da Republica. O fim desta guerra se acabará na Santa Casa de Roma e o sangue há de ir até a junta grossa. (Os sertões, 2002, p.176)

No discurso sebastianista do pregador de Canudos, era a república a lei do cão e somente um grande libertador para tirar o povo da ilusão a que fora submetido. Notar nas quadrinhas encontradas nos despojos do Canudos pós-guerra o reflexo dessas pregações. Anônimas e, portanto, de sabor folclórico, as trovas transcritas por Euclides da Cunha dizem do pensamento antirrepublicano de toda a comunidade conselheirista:

\author{
Sahiu D. Pedro segundo \\ Para o reyno de Lisboa \\ Acabosse a monarquia \\ O Brazil ficou atôa! (Os sertões, 2002, p. 210)
}

Vale notar o caráter popular da seita sebastianista canudense e a desinformação do grupo. D. Pedro II é exilado na França. Não poderia de forma alguma, por questão de foro político, ir para Lisboa. Isso já basta para justificar a ingenuidade de Antônio Conselheiro e de seu séquito. Mas a república é ainda o alvo dos crentes de Canudos, de acordo com as quadrinhas abaixo:

Garantidos pela lei

Aqueles malvados estão

Nós temos a lei de Deus

Eles tem a lei do cão!

Bem desgraçados são elles

Pra fazerem a eleição

Abatendo a lei de Deus

Suspendendo a lei do cão!

Casamento vão fazendo

Só para o povo iludir

Vão casar o povo todo

No casamento civil! (Os sertões, 2002, p. 210-211) 
Para Conselheiro, a salvação estaria por chegar. A república haveria de cair por terra e a monarquia haveria de voltar. O reflexo disso uma vez mais se depreende das quadrinhas com D. Sebastião a por fim a lei do cão:

\author{
D. Sebastião já chegou \\ E traz muito regimento \\ Acabando com o civil \\ E fazendo casamento! \\ $\mathrm{O}$ anticristo nasceu \\ Para o Brazil governar \\ Mas ahi está o Conselheiro \\ Para delles nos livrar!
}

\author{
Visita nos vem fazer \\ Nosso rei D. Sebastião. \\ Coitado daquele pobre \\ Que estiver na lei do cão! (Os sertões, 2002, p. 211)
}

Para o santo Conselheiro a lei do cão é a república, pois esta traz uma nova lei, faz casamento fora da igreja, o casamento civil, cobra impostos, entre outras novidades que se implantam nessa nascente forma de governo. Em suma, o Conselheiro não reconhecia a república, não obedecia a ordens dela provinda e chega a reagir a mandado de prisão oficial, o que não faria com relação ao regime monárquico, a que reconhecia. (Cf. Os sertões, 2002, p. 214).

\title{
Exaltação a Conselheiro, Profeta de Canudos
}

Os poetas Ivanildo Vila Nova e Bráulio Tavares, num canto sertanejo de libertação, como um mantra messiânico, trazem à memória Antônio Vicente Mendes Maciel, o Antônio Conselheiro, e Virgulino Ferreira da Silva, o Lampião como figuras representativas e incontestáveis de heróis nordestinos. O texto chama-se Nordeste independente, e consta de um então LP homônimo, lançado por Elba Ramalho no início da década de 80, momento histórico em que se vivia sob a ditadura militar. Foi proibido de execução pública por ser entendido como protesto de feição política, o que era de se esperar da conjuntura política da época. O canto é de esperança e de fé numa terra cujo povo luta desde os tempos coloniais por crescimento e liberdade e para o qual Conselheiro, Lampião e outros ícones locais sempre serão referencial de heroísmo messiânico: 
Em Recife, o Distrito Federal.

O idioma ia ser nordestinense

A bandeira, de renda cearense

Asa branca era o Hino Nacional

O folheto era o símbolo oficial

A moeda, o tostão de antigamente

Conselheiro seria o inconfidente

Lampião, o herói inesquecido

Imagine o Brasil ser dividido

E o Nordeste ficar independente!

Resta lembrar que o messianismo bíblico é a expectativa da vinda de um escolhido para salvar e libertar seu povo. Precisamente messias, do hebraico, mashiah, vem a ser aquele que é ungido, a quem se espera. Messias é um escolhido de Deus para cumprir missão especial.

$\mathrm{Na}$ antropologia social, messianismo vem a ser qualquer movimento político-religioso baseado na crença em um enviado divino (já presente ou ainda por vir) que anuncia e prepara a abolição das condições vigentes, e por fim instaura uma era de plena felicidade e justiça.

Aplica-se o termo especialmente quando determinada crença pode ser considerada uma referência ideológica para grupos e povos em situação de crise e de dominação, por exemplo, em contexto de domínio colonial.

O Messias é, portanto, a pessoa a quem Deus comunica algo de seu poder e autoridade. É pessoa carismática e esperada ansiosamente.

Na história dos povos há sempre uma situação em que a esperança na vinda de um messias sempre foi patente. Nessa conotação o messias é uma entidade salvadora, redentora, independentemente de feições cristãs ou pagãs, messias é aquele a partir do qual se esperam mudanças.

Há de se notar que nos tempos mosaicos fora feita uma promessa da vinda de um libertador, ao povo hebreu:

Portanto o Senhor mesmo vos dará um sinal: Eis que a virgem conceberá e dará à luz um filho, e lhe chamará Emanuel. Ele comerá manteiga e mel quando souber desprezar o mal e escolher o bem (Livro de Isaías, cap. 7. v. 14).

Conforme prometido, nos tempos neotestamentários, e segundo a crença judaico-cristã, surge o messias, a trazer a esperança em tempos melhores e promissores: 
Ela dará à luz um filho e lhe porás o nome de Jesus, porque Ele salvará o seu povo dos pecados deles. Ora, tudo isto aconteceu, para que se cumprisse o que fora dito pelo senhor profeta por intermédio do profeta: Eis que a virgem conceberá e dará à luz um filho e Ele será chamado pelo nome de Emanuel (Livro de Mateus, cap. 1, vv 21-23).

No universo ainda pagão, Vergílio, na Bucólica IV, faz referência ao nascimento de um menino que irá restaurar a humanidade, trará a Idade de Ouro de volta e anunciará uma Nova Era:

\author{
A última idade já chegou da predição de Cumas: a grande ordem dos séculos \\ de novo ei-la que nasce. \\ Também já volta a virgem, volta o reino de Saturno; \\ Já uma nova progênie desce dos mais altos céus. \\ Casta Lucina, ampara, que já reina o teu Apolo, \\ o menino que está nascendo: a geração de ferro com ele findará, \\ ao mundo vindo a raça de ouro (Bucólicas IV - Polião, v. 4-10).
}

A poesia acima transcrita termina por trazer as cores de um messianismo cristão que é identificado pela igreja dos tempos de Constantino e de Santo Agostinho como aquele representado pela figura do próprio Jesus Cristo.

\title{
Considerações Finais
}

Tentar entender o fenômeno do messianismo e, especificamente, daquele ocorrido em Portugal, e que toma corpo na figura lendária de D. Sebastião, é tentar compreender a história dos povos do ocidente, principalmente por viver este povo a cultura da esperança e da volta de um messias, com base, sobretudo, na cultura judaico-cristã. É buscar compreender ainda, que a cultura da volta de um messias se dá, desde períodos anteriores como no paganismo greco-romano, em que já havia a esperança da volta à Idade de Ouro, que só seria possível com o advento de um menino que viria a ser o referencial de uma Nova Era. Desse modo, entendemos que há um messianismo anterior ao cristianismo, assim como o sebastianismo-messiânico português antecede a D. Sebastião.

Compreendemos ainda como foi intenso o sebastianismo brasileiro da primeira e segunda metade, respectivamente, do século XIX e como foi esse culto arraigado em nossa realidade, ao ponto de se chegar às raias da violência tanto oficial quanto de messianistas folclóricos, mas crentes e, por isso, detentores da força e da resistência para a defesa individual e do grupo a que pertenceram. Entender o messianismo- sebastianista ocorrido em nossa história é tentativa de entender a nossa realidade de esperança e fé. E entender nossa formação como povo brasileiro. 


\section{Referências}

BÍBLIA SAGRADA. RJ. Sociedade Bíblica do Brasil, 1983.

CUNHA, E. Os Sertões, Record, 2002.

LUCCOCK, J. Notas sobre o RJ. Martins Editora, 1942.

PESSOA. F. Mensagem, Martin Claret, 1998.

RIBEIRO, L. T. (1986). Rio de Janeiro: Funarte/Instituto Nacional do Folclore, 1986.

SPIX, J. B. e MARTIUS, C.F. . Trad. Lúcia Furquim Lahmeyier. Viagem pelo BRASIL. São Paulo: Edusp, 1981. 